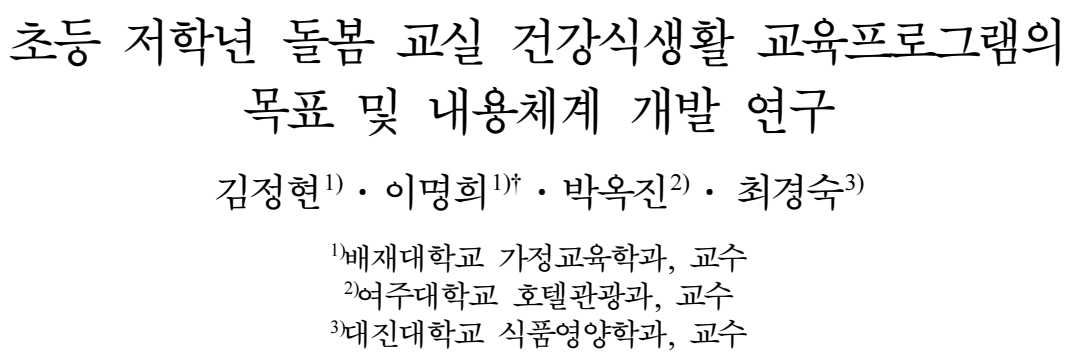

\title{
A Study on the Development of the Goals and Contents System of Healthy Dietary Education Program for After-School Care in Lower Grade in Elementary School
}

\author{
Jung-Hyun Kim ${ }^{1)}$, Myoung Hee Lee ${ }^{1)^{\dagger}}$, Okjin Park' ${ }^{2}$, Kyung Sook Choi ${ }^{3)}$ \\ ${ }^{1)}$ Department of Home Economics Education (Major of Food and Nutrition), PaiChai University, Daejeon, Korea, Professor \\ ${ }^{2)}$ Department of Hotel \& Tourism, Yeoju Institute of Technology, Gyeonggi-do, Korea, Professor \\ ${ }^{3)}$ Department of Food and Nutrition, Daejin university, Gyeonggi-do, Korea, Professor
}

Corresponding author Myung-Hee Lee

Department of Home Economics Education (Major of Food and Nutrition), PaiChai University, 155-40, Baejae-ro, Seo-gu, Daejeon 35345, Korea

Tel: (042) 520-5423

Fax: 070-4362-6292

E-mail:mhlee@pcu.ac.kr ORCID: 0000-0002-9588-5408

Acknowledgments

*This research was supported by a grant from Korea Health Promotion Institution in 2016.

Received: December 28, 2018 Revised: January 14, 2019 Accepted: January 14, 2019

\section{ABSTRACT}

Objectives: The study purpose is to develop a content system for a healthy dietary education program for after-school care in lower grade in elementary school.

Methods: The contents of healthy dietary education in the 2015 revised curriculum and textbooks and the major education programs related to dietary life that are currently used in elementary school education were analyzed. Focus group interviews were held with field experts related to lower grade in elementary care class. Accordingly, the structuring of the education area and the detailed education contents were systematized.

Results: From the analysis results, the contents of curriculum, textbook, and administrative department were classified as hygiene safety, health, and culture. The goal of the educational content system was divided into three areas: nutritional dietary life, food hygiene and health, and food culture. The subjects consisted of dietary balance, healthy body weight, digestion and absorption, food hygiene, Korean agricultural products, traditional food, and table manners. The curriculum was composed of 12 content elements.

Conclusions: In order to ensure that after-school care students can grow into healthy, growth-oriented and creative talents, the role of the caring guide is important, and associated guidelines are needed in the future.

Korean J Community Nutr 24(1): 24 37, 2019

KEY WORDS healthy dietary education program, after-school care, lower grade in elementary school

This is an Open-Access article distributed under the terms of the Creative Commons Attribution Non-Commercial License (http:// creativecommons.org/licenses/by-nc/3.0) which permits unrestricted non-commercial use, distribution, and reproduction in any medium, provided the original work is properly cited. 


\section{서 론}

여성의 사회 진출이 활발해짐에 따라 맞벌이 가정이 늘어 나게 되었고, 경제적 어려움으로서 가족 해체의 어려움을 겪 게 되는 경우가 많아짐에 따라 한 부모 가정, 저소득층 가정, 다문화가정 및 맞벌이 가정 등 다양한 형태의 가족 구성원이 나타나게 되었다. 이로 인하여 양육 및 보육이 취약한 가정 들이 증가하게 되었고 사회 각 분야의 보호 및 교육을 필요 로 하는 초등학교 저학년 아동의 경우 효율적으로 보낼 수 있는 방과 후 활동 등 사회적 책임이 대두되었다 $[1,2]$. 특 히 초등 돌봄교실은 학교의 교육기능에 보육기능을 확대하 여 소외계층이나 보호를 필요로 하는 학생들에게 서비스를 제공하기 위한 제도로 [3] 정규수업 시간 이외에 돌봄이 필 요한 학생들을 위한 프로그램으로 아침, 오후, 저녁 돌봄으 로 구분되며, 돌봄 학생 가정 부모의 퇴근 시간 등을 고려하 여 학교 여건에 따라 탄력적으로 운영하는 교육활동을 말한 다 [4]. 그러나 아직까지 초등 돌봄교실은 운영 및 안전과 관 련된 지침 이외에 교육프로그램 컨텐츠가 매우 미흡하며, 지 역별 예산 및 교사 역량에 따라 운영의 질적 차이가 발생하 고 있는 실정이다. 더욱이, 초등 돌봄교실의 급 · 간식의 경 우 위생과 안전의 이유로 완제품 간식 및 매식 급식을 원칙 으로 하고 있으며 학교급식의 범위에서 제외되고 있다. 간식 의 경우 채소 - 과일이 배제된 과자, 빵, 가공우유 위주로 배 식되어 아동의 영양불균형 및 건강한 식습관 형성 저해 우려 가 있다 [5].

올바른 식습관과 영양섭취는 성장하는 어린이들의 신체적 발달 뿐 아니라 정신적 능력과 지적 능력의 발달에도 크게 관 여 하며, 특히 초등학교 시기는 자아개념의 발달이 이루어지 는 시기인 만큼 올바른 식생활행동 형성은 건강한 성인이 되 고 이를 유지하는 밑바탕이 된다 [6]. 최근, 전체적으로 급속 한 경제성장으로 인해 가족의 형태가 핵가족과 맞벌이 가족 으로 바뀌면서 가정에서 식습관을 지도할 사람이 적어지고 기회도 적어져 또래 친구나 디지털매체의 영향에 의한 식생 활행동이 형성되고 있는 경우가 많으며, 가족의 형태 변화에 의해 혼자 식사하는 아동이 점점 많아지고 있어 매끼를 어머 니에 의해 관리 되는 것이 아니라 아동 스스로 선택하고 결 정 하는 빈도가 높아지고 있다 $[7,8]$. 최근 초등학생을 대상 으로 한 연구에 의하면 아동의 구매 행위에서 가장 많은 비 중을 차지하는 것은 식품 구매로 나타났는데, 이는 아동들이 과거에 비해 식품 구매자, 소비자로서 중요한 위치에 서게 되 었음을 의미하며 [9], 올바른 식품 섭취를 유도하기 위한 식 생활지도가 매우 중요하다[10, 11].
초등학교에서의 식생활 교육은 전 교과에 산재해 있으며 독립된 식생활 교과가 없어서 체계적인 식생활 교육이 어려 운 실정이다. 효율적인 식생활 교육을 위해서 무엇보다 각 교 과에서 중복되어 다루어지고 있는 식생활교육영역의 체계적 인 통합지도가 필요하며 자주적인 학습력과 문제해결력을 기 르기 위해서는 분과된 학문적 접근보다는 통합적 접근을 통 한 식생활 교육이 바람직하다[12]. 2006년 7월 법률 제 7962호 ‘학교 급식법'을 개정하면서, 각 학교에 영양교사를 배치하고 식생활 지도와 영양 상담을 실시하도록 규정하고 있어, 이후 지속적으로 영양교육을 실시하였음에도 불구하 고, 2013 년도 국민건강영양조사에 의하면 1년 이내에 영양 교육 및 상담을 받아본 경험이 있는 초등학생이 $27.4 \%$ 로 실 제 수혜율이 저조한 실정이다. 학생들을 대상으로 한 영양교 육의 효과로 영양교육 후 영양지식 변화, 긍정적인 방향으로 의 식행동 변화, 신체 변화, 생화학적 변화 등에 대한 많은 연 구 결과들이 보고되고 있으나 학생들의 현행 영양교육에 대 한 인식과 만족도에 대한 연구는 미비한 실정이다 [13].

현재 우리나라 학교교육을 기반으로 한 초등학생을 위한 건강식생활 관련 교육프로그램은 다양한 기관에서 지속적으 로 이루어지고 있지만 대부분의 교육 내용은 영양 및 요리 등 에만 치우쳐 있다. 초등학생을 대상으로 진행하고 있는 건강 식생활 관련 분야에 대한 체계적인 교육 프로그램은 매우 부 족한 실정이고 초등학생의 발달 특성 및 상황 등을 고려하지 않고 단편적이고 개별적인 차원에서 일회성 교육이 이루어 지고 있는 경우가 많다. 초등학교 저학년은 건강생활습관 형 성에 중요한 시기이다[14]. 저학년일수록 올바른 식습관을 형성하기가 쉬우므로 실천을 중시하는 영양교육에서는 저학 년부터 체계적인 영양교육의 실시가 이루어져야하며, 이는 고학년까지 지속되어야 추후 청소년기를 지나 성인기가 되 어서도 긍정적인 식태도가 유지될 가능성이 높다고 사료된 다[15]. 이에 본 연구에서는 보육의 기능을 더해 운영되어 야 하는 돌봄교실에 적용 가능 한 초등 저학년의 수준별 최 근의 식생활 실태를 조사 - 적용하여 초등 돌봄교실 학생들 의 식품 안전과 영양 교육을 모두 포함하는 수준별 건강식생 활 교육프로그램의 내용체계를 개발하고자 하였다.

\section{연구내용 및 방법}

\section{1. 연구내용}

초등 저학년 돌봄교실은 초등학교 공교육 현장과 연계되 어 이루어지는 일련의 교육활동이므로, 돌봄교실을 통한 건 강식생활 교육이 성립되려면 교육의 목적과 내용, 교수학 습방법, 평가 등이 교육과정을 기반으로 체계적으로 구성 
되어 있어야 함으로 이에 대한 분석을 수행하였다. 이를 토 대로 초등학교 저학년 학교교육 연장선에서 운영되고 있는 돌봄 교실에서 어떻게 구현할 것인가에 대한 내용 영역을 설정하고 내용 요소를 추출하여, 전문가 집단의 검증을 통 하여 건강식생활 교육 프로그램으로 개발하는데 근거가 되 고자 하였다.

\section{2. 연구방법}

\section{1) 2015 개정 교육과정 및 교과서 내 건강식생활 교육내용 분석}

초등 저학년 교육과정은 일반 교과와 통합교과로 나누 어져 있으며 이 중 건강식생활 내용을 다루고 있는 통합교 과인 ‘바른생활', ‘슬기로운 생활', ‘즐거운 생활' 교과에서 학습하는 건강식생활 관련 핵심개념과 학습요소 및 교육 목표를 분석하였다. 저학년 일반 교과는 국어, 국어활동, 수학, 수학익힘 등으로 통합교과를 포함하여 교과서에 제 시된 건강식생활과 관련된 단어, 문구, 삽화 등의 내용요 소를 분석하였다.

\section{2) 초등교육 현장 활용 식생활 관련 교재 분석}

현재 초등학교 학교교육 현장에서 활용되고 있는 식생활 관련 주요 교육 프로그램을 분석하였다. 식품의약품안전처 에서 개발한 초등학교 영양교사 대상의 저학년-중학년-고 학년 식품안전 · 영양교육 프로그램과 농림축산식품부에서 개발하여 지역의 식생활교육 네트워크 식생활강사들이 활용 하고 있는 식생활 교육 프로그램, 그리고 각 시도 교육청 및 정부출연 기관 등에서 개발되어 활용되고 있는 다양한 프로 그램을 매체별로 구분하여 분석하였다.

\section{3) 현장 전문가 심층 면담}

초등 저학년 돌봄교실 관련 현장 전문가들을 대상으로 심 층 면담을 진행하였다. 이에 앞서 본 연구에 대한 배재대학 교 기관생명윤리위원회 (IRB) 의 승인을 받아 진행하였다 (PCU IRB No.2-1040766-AB-N-01-201607). 서울 및 경기도 지역 소재 돌봄교실 담당 교사 5 인, 영 양교사 1 인, 돌봄 전담사 4 인을 대상으로 진행하였다. 자료 수집의 기간은 2016년 4월부터 2016년 6월까지 약 두 달 간에 걸쳐 시행되었다. 심층면담은 2 차에 걸쳐 진행되었으 며, 초등 돌봄교실 건강식생활교육 프로그램의 목표 설정 및 내용체계 구성을 위해 초등 돌봄교실의 내 건강식생활교 육 프로그램의 당위성과 초등 저학년 돌봄교실의 배경과 특 성에 대하여 면담 2 주전 이메일로 발송한 후, 면담을 진행 하였다.
현장 전문가 심층 면담의 진행은 초등돌봄교실 건강식생 활교육프로그램의 목표설정과 내용 체계 구성이 도출 가능 한 사전 준비된 설문지를 활용하여 자유로운 분위기 속에 토 론이 가능하였고, 사전 작성 질문지를 기반으로 반구조화 면 담 형식으로 진행되었다. 사전 질문지의 내용은 2015 개정 교육과정 및 교과서 분석 내용 및 현재 초등학교 현장에서 활 용되고 있는 식생활 관련 교재 내용 요소 분석 결과를 기반 으로 초등 저학년 돌봄교실 내 식생활교육프로그램 개발 시 목표 설정에 관한 의견과 초등 저학년을 대상으로 얻어질 수 있는 가치 및 영역 범주화에 관한 질문들로 구성되었다. 초 등 저학년 돌봄교실 건강식생활교육 프로그램의 목표 설정 및 내용 체계 구성을 위하여 초등 1-2학년의 신체적, 심리 적, 사회적, 인지적 관점에서 바라본 유형별 발달의견을 파 악하였으며 현재 초등 저학년 돌봄교실을 운영하고 있는 실 무자들과의 면담을 통해 발생 가능한 건강식생활교육프로그 램 운영상 문제점과 그 해결책을 함께 모색하였다.

\section{4) 건강식생활 교육 프로그램의 교육 목표 설정 및 내용 체계화}

초등 저학년 돌봄교실 건강식생활 교육을 위하여, 목표를 설정하고 이에 따라 교육 영역 구조화와 이에 따른 상세 교 육내용을 체계화 하였다. 초등학생 발달 단계에 따른 내용과 수준의 범위를 고려하였으며, 학습 내용 요소는 초등학교 저 학년 수준에 맞추어 난이도를 조절하여 학생들이 이해하기 쉽게 구성할 수 있도록 하였다.

초등 저학년 교육과정 기반으로 내용 체계 구성의 차별성 과 주요 강조점 부각, 용어의 통일 등에 대한 검토를 하였으 며, 초등 저학년 돌봄교실 건강식생활 교육프로그램의 개발 방향 설정 및 교육적 가치를 모색하는데 반영될 수 있도록 하 였다. 초등 저학년 돌봄교실 건강식생활 교육 프로그램의 목 표 설정 및 내용 체계 구성에 관한 교육적 관점과 초등 1-2 학년의 신체적, 심리적, 사회적, 인지적 관점에서 접근할 수 있도록 하였다. 이는 초등학생 저학년 학습자의 흥미와 적성 에 맞는 수요자 중심의 프로그램을 개발 - 운영하여 가정처 럼 따뜻한 보육활동 및 초등 저학년 학생들과 학부모들의 요 구에 부응하는 교육활동으로 개발될 수 있도록 하였다. 이는 방과 후 돌봄교실은 학교 교육의 연장선으로 학부모들이 사 교육비를 절감할 수 있으며 공교육에 대한 신뢰도를 제고하 고자 하는 목적과 함께, 무엇보다도 초등학교 저학년 학생들 이 올바른 식생활 행동 확립 및 영양섭취를 통하여, 신체적 발달 뿐 아니라 정신적 능력과 지적 능력의 발달에도 크게 관 여하여 궁극적으로 건강하게 성장할 수 있도록 하는데 가장 큰 목적이 있다. 


\section{결 과}

\section{2015 초등 저학년 교육과정 및 교과서 내용 분석 \\ 1) 교육과정 내 건강식생활 관련 학습요소}

초등 저학년 교육과정 중 건강식생활과 관련된 내용을 Table 1에 제시하였다. 건강식생활 내용이 다루어지는 영역 은 ‘학교'와 '계절', '나라'였으며, 교육목표는 건강 유지와 관리를 위한 습관을 함양하는 것으로 볼 수 있었다. 학습 요 소는 몸과 마음의 건강을 유지하는 내용으로 제시되어 있으 며, 또한 계절에 대한 내용으로 날씨 변화에 따른 건강관리 에 대한 내용을 다루고 있다. '나라' 영역에서는 우리나라 문 화적 특징으로 생활 문화 속에서의 식생활 내용이 제시되고 있었다.

\section{2) 교과서 내 건강식생활 내용 요소}

2015 1학년, 2학년 교과서에 제시된 건강 식생활 관련 내 용요소를 각각 Table 2와 3에 제시하였다. 국어, 국어활동, 수학, 수학익힘, 봄, 여름, 가을 그리고 겨울 등의 교과서에 이미지와 삽화 그리고 낱말과 문구 등으로 건강식생활 관련 내용 요소 등이 제시되어 있었다.
1 학년과 2 학년 교과서에는 기본적으로 다양한 식품들이 많이 제시되고 있었으며, 식생활 관련 모습과 행동이 제시되 어 있었다. 식품은 채소와 과일이 가장 많이 등장하고 있었 으며, 그 다음으로는 곡류로 나타났다. 이외에도 떡 종류와 한국 전통음식 등이 제시되어 있었다. 2 학년에는 식품의 종 류가 다양해진다. 특히 간식의 종류가 다양하게 제시되고 또 한 세계의 음식이 제시되고 있다. 행동은 가족과 학교 급식, 그리고 시장과 농장 등에서 보이는 모습들이었다. 또한 가정 에서의 식생활 행동과 또래 집단에서 나타나는 행동으로 주 로 긍정적인 행동이 제시되어 있었다. 주요 행동은 채소와 과 일의 수확이 가장 많았으며 다음으로는 조리가 많이 등장하 였다. 2학년에 보다 구체적인 식생활 행동이 나타나 다양한 채소와 과일의 수확이 제시되고 생산, 조리, 판매 등과 관련 된 다양한 직업을 보여주고 있다.

\section{2. 초등학교 현장 활용 건강식생활 관련 교육 프로그램}

현재 초등학교 현장에서 활용되고 있는 건강식생활 관련 교육 프로그램을 Table 4에 제시하였다. 교육도구는 교재, 매뉴얼, PPT 및 리플렛 형식으로 개발되어 있었고 개발 주 최는 식품의약품안전처, 농림축산식품부, 보건복지부, 한국 건강증진개발원, 한국보건사회연구원 그리고 시도 교육청 등

Table 1. 2015 Contents regarding healthy dietary in lower grade in elementary school education

\begin{tabular}{|c|c|c|c|c|c|c|}
\hline Subject & $\begin{array}{l}\text { Text } \\
\text { book }\end{array}$ & Chapter & $\begin{array}{l}\text { Key concepts } \\
\text { (Subcategory) }\end{array}$ & $\begin{array}{l}\text { Learning } \\
\text { elements }\end{array}$ & $\begin{array}{l}\text { Educational } \\
\text { objective }\end{array}$ & $\begin{array}{l}\text { Content } \\
\text { element }\end{array}$ \\
\hline Disciplined living & School & $\begin{array}{l}1.2 \\
\mathrm{Me}\end{array}$ & $\begin{array}{l}\text { The health of the body and } \\
\text { soul }\end{array}$ & $\begin{array}{l}\text { Rules, health, cleanliness. } \\
\text { and cooperation }\end{array}$ & $\begin{array}{l}\text { To maintain the health } \\
\text { of my body and }\end{array}$ & Health \\
\hline Wise living & & & $\begin{array}{l}\text { - Knowing each part of the } \\
\text { body } \\
\text { - Exploring my talents and } \\
\text { interests }\end{array}$ & & soul. & Health \\
\hline Fun living & & & $\begin{array}{l}\text { - My body, senses, } \\
\text { expression of feelings } \\
\text { - A performance and exhibit } \\
\text { about me }\end{array}$ & & & Health \\
\hline $\begin{array}{l}\text { Disciplined living } \\
\text { Wise living }\end{array}$ & Spring & $\begin{array}{l}2.1 \\
\text { Spring }\end{array}$ & $\begin{array}{l}\cdot \text { Health and hygiene } \\
\text { · Understanding spring } \\
\text { weather and lifestyle } \\
\text { · Life hacks of spring }\end{array}$ & $\begin{array}{l}\text { Changes in weather. } \\
\text { health care. nature } \\
\text { conservation. } \\
\text { respect for life }\end{array}$ & $\begin{array}{l}\text { To know the changes } \\
\text { of spring weather } \\
\text { and develop a } \\
\text { habit of following }\end{array}$ & $\begin{array}{l}\text { Health } \\
\text { Health }\end{array}$ \\
\hline Fun living & & & $\begin{array}{l}\text { - Feeling expression of spring } \\
\text { - Decorating the house }\end{array}$ & & my own nealtn rules. & Health \\
\hline Wise living & Fall & $\begin{array}{l}6.2 \\
\text { What fall } \\
\text { looks like }\end{array}$ & $\begin{array}{l}\text { - Chuseok,seasonal customs } \\
\text { - Leaves, fruits }\end{array}$ & $\begin{array}{l}\text { Fall weather and lifestyle, } \\
\text { characteristics of fall, } \\
\text { Chuseok, }\end{array}$ & $\begin{array}{l}\text { To learn about } \\
\text { Chuseok and } \\
\text { compare it to other } \\
\text { seasonal customs. }\end{array}$ & Eating habits \\
\hline Wise living & Country & $\begin{array}{l}7.1 \\
\text { Our } \\
\text { country }\end{array}$ & $\begin{array}{l}\text { - Our country's symbols and } \\
\text { culture } \\
\text { · Lifestyle and culture of } \\
\text { South Korea and North } \\
\text { Korea }\end{array}$ & $\begin{array}{l}\text { Our country's symbols } \\
\text { and culture, lifestyle of } \\
\text { South Korea and North } \\
\text { Korea, }\end{array}$ & $\begin{array}{l}\text { Inquire into our } \\
\text { country's symbols } \\
\text { and culture and } \\
\text { gather materials for } \\
\text { an introduction. }\end{array}$ & Eating habits \\
\hline
\end{tabular}


28 - 초등돌봄건강식생활 교육

Table 2. Content elements regarding healthy dietary proposed in the Grade 1 curriculum

\begin{tabular}{|c|c|c|c|}
\hline Grade & $\begin{array}{l}\text { Text } \\
\text { book }\end{array}$ & & Content Elements \\
\hline \multirow[t]{12}{*}{$\begin{array}{l}\text { Grade } 1 \\
\text { Term } 1\end{array}$} & \multirow[t]{2}{*}{ Korean A } & $\begin{array}{l}\text { Illustrations/ } \\
\text { Images }\end{array}$ & $\begin{array}{l}\text { - Food - Fresh fruits, various fruits, fruits and vegetables from a traditional market } \\
\text { - Behavior - Traditional markets, etiquette before having a snack, school meal room }\end{array}$ \\
\hline & & $\begin{array}{l}\text { Words } \\
\text { /Phrases }\end{array}$ & $\begin{array}{l}\text { - Food - Eggplant, tree, strawberry, acorn, lemon, quince, peach, apple, cherry, plum, Korean } \\
\text { melon, bean, tomato, grape, pumpkin, daikon, green onion, cucumber, bellflower, sweet } \\
\text { potato, banana, milk, plum, chili, cucumber, duck, Korean wild grape, sweet potato, Japanese } \\
\text { apricot }\end{array}$ \\
\hline & \multirow[t]{2}{*}{ Korean B } & $\begin{array}{l}\text { Illustrations/ } \\
\text { Images }\end{array}$ & $\begin{array}{l}\text { - Food - bean, green onion, daikon, soup, cotton candy } \\
\text { - Behavior - Picking apples, meal, birthday meal, offering rice cakes, having a meal, receiving a } \\
\text { birthday cake }\end{array}$ \\
\hline & & $\begin{array}{l}\text { Words } \\
\text { /Phrases }\end{array}$ & - Food - bean, green onion, daikon, soup, cotton candy, apple, rice cake \\
\hline & \multirow[t]{2}{*}{$\begin{array}{l}\text { Korean } \\
\text { Activities }\end{array}$} & $\begin{array}{l}\text { Illustrations } \\
\text { / Images }\end{array}$ & $\begin{array}{l}\text { - Food - Sweet potato, banana, summer watermelon, grape, duck, daikon, barley, eggplant, } \\
\text { acorn, tofu, walnut, cucumber, green onion, chili, milk, tomato, bellflower, plum, meat, Korean } \\
\text { pear, Korean melon, cracker, apple, persimmon, chestnut, roasted seaweed, adzuki bean, } \\
\text { market, Kimbap, lunch, strawberry, peanut, bread, stew, lettuce, carrot, potato, sweet pumpkin, } \\
\text { corn, peach, orange, Kimchi, beverage, mackerel, squid } \\
\text { - Behavior - Lunch, a father making fried rice, lunch time at school }\end{array}$ \\
\hline & & $\begin{array}{l}\text { Words } \\
\text { /Phrases }\end{array}$ & $\begin{array}{l}\text { - Food - Sweet potato, banana, watermelon, grape, cooking, eggplant. acorn, tofu, walnut, } \\
\text { cucumber, green onion, chili, milk, tomato, conch, daikon, bellflower, plum, meat, pear, Korean } \\
\text { melon, cracker, apple, persimmon, chestnut, roasted seaweed, adzuki bean, peach, } \\
\text { clementine, corn, sweet pumpkin, carrot, lettuce, potato, mackerel, squid, beverage, Kimchi, } \\
\text { Kimbap, shrimp, honey strawberry, peanut, bread, stew, dumpling, ramen, milk, vinegar }\end{array}$ \\
\hline & Math & $\begin{array}{l}\text { Illustrations } \\
\text { / Images }\end{array}$ & $\begin{array}{l}\text { - Food - Strawberry, candy, birthday party, muffin, eating rice cakes, chocolate, tomato } \\
\text { - Behavior - A child picking apples, harvesting on a farm, kids picking strawberries, kids picking } \\
\text { Korean melons, kids holding canned potatoes, collecting tomatoes, counting cucumbers, filling } \\
\text { the basket with eggs }\end{array}$ \\
\hline & \multirow[t]{2}{*}{$\begin{array}{l}\text { Math } \\
\text { Practice }\end{array}$} & $\begin{array}{l}\text { Illustrations } \\
\text { / Images }\end{array}$ & $\begin{array}{l}\text { - Food - Orange, strawberry, tomato, cupcake, apple, cup yogurt, ice cream, slice of cake, egg, } \\
\text { spoon, Korean melon, Korean pear } \\
\text { - Behavior - A mother who bought bread, candles on a birthday cake, strawberry farm }\end{array}$ \\
\hline & & $\begin{array}{l}\text { Words } \\
\text { /Phrases }\end{array}$ & - Food - Plum, \\
\hline & \multirow[t]{2}{*}{ Spring } & $\begin{array}{l}\text { Illustrations } \\
\text { / Images }\end{array}$ & $\begin{array}{l}\text { - Behavior - Receiving food in school meal room, planting seeds, how to make daikon sprout, kids } \\
\text { picking up apples }\end{array}$ \\
\hline & & $\begin{array}{l}\text { Words } \\
\text { /Phrases }\end{array}$ & - Food - Bean, bean sprout, steamed rice cake \\
\hline & Summer & $\begin{array}{l}\text { Illustrations } \\
\text { / Images }\end{array}$ & $\begin{array}{l}\text { - Food - Patbingsu, ice water, watermelon, ice cream } \\
\text { - Behavior - A cooking father, a cooking mother, a family eating together, a family celebrating a } \\
\text { birthday together, a child wandering about with a spoon, a family eating watermelon together, } \\
\text { a child drinking water, a child eating ice cream, a child eating chicken soup with ginseng, a } \\
\text { family eating Patbingsu, putting food in the fridge, closing the fridge, a family harvesting } \\
\text { potatoes together }\end{array}$ \\
\hline \multirow[t]{3}{*}{$\begin{array}{l}\text { Grade } 1 \\
\text { Term } 2\end{array}$} & Korean A & $\begin{array}{r}\text { Illustrations } \\
\text { / Images }\end{array}$ & $\begin{array}{l}\text { - Behavior - Picking acorns, Doljabi, eating fried tofu rice balls on a trip, eating Kimbap and } \\
\text { sandwiches on a trip, parents making fried rice and eggs, talking about becoming a chef, the } \\
\text { story about a pea and a calf, traditional market, eating well }\end{array}$ \\
\hline & \multirow[t]{2}{*}{ Korean B } & $\begin{array}{r}\text { Illustrations } \\
\text { / Images }\end{array}$ & $\begin{array}{l}\text { - Behavior - The story about a salt-making millstone, eating cotton candy, lunch at school, making } \\
\text { Songpyeon, beating and coiling it on the floor of a traditional house, a child eating lunch at } \\
\text { school }\end{array}$ \\
\hline & & $\begin{array}{l}\text { Words } \\
\text { /Phrases }\end{array}$ & - Food - Rice, millstone, salt, unhulled rice \\
\hline
\end{tabular}


Table 2. continued

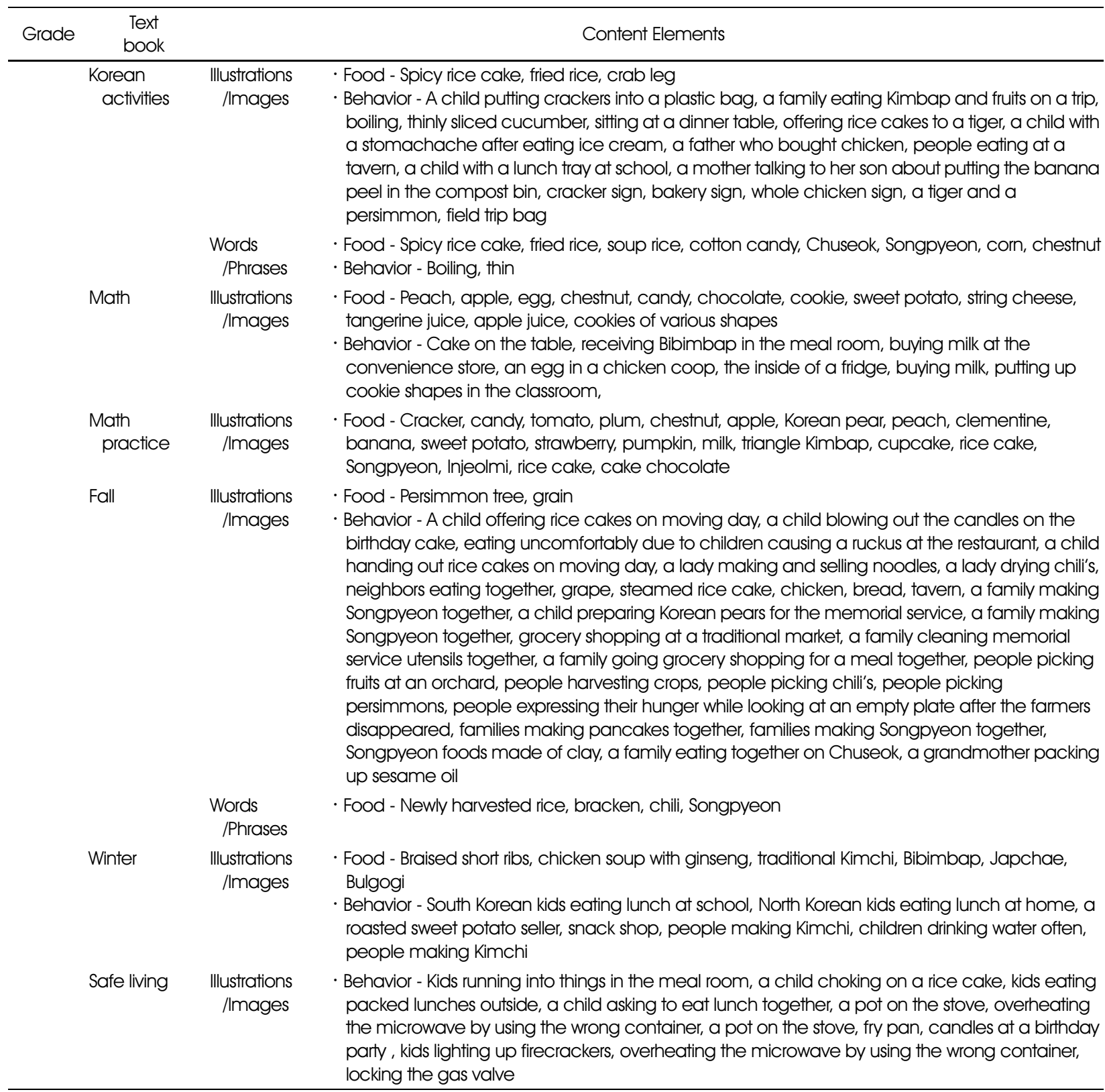

에서 개발되고 있었다. 주요 내용을 살펴보면, 어린이의 올 바른 식습관 형성을 위해 영양-건강 관련 주제와 농업과 미 각을 연결하는 식생활 주제로 ‘오감 녹색식생활', ‘오감으로 즐기는 우리음식', ‘식품알레르기' 등이 있었다. 또한 식문 화, 식품, 식습관, 위생과 환경, 조리 등의 내용 등이 구성되 어 있음을 알 수 있었다. 제시되고 있는 교수학습 방법은 사 진, 만화, 활동지등의 형식으로 실제 수업에서 활용할 수 있 도록 제작되어 있었다. 식생활교육과 영양교육 지도서 등은 학년별 수준별 영양교육 프로그램으로 구성되어 있었다. 초 등학교 현장에서 활용되고 있는 교재 및 교육 활동 자료들은
교사용 지도서와 학생용 교재로 구성되어 있으며, 학생용은 생각열기, 활동 등으로 제시되어 있었다. 특히, 초등 저학년 인 1학년과 2학년의 교육내용으로 제시되고 있는 주제들을 살펴보면, 건강의 중요성, 식품에 대한 내용, 골고루 먹기, 열 량에 대한 내용, 채소와 과일, 아침밥, 간식, 당, 나트륨, 우리 농산물, 등에 관한 내용들로 구성되어 있었다. 또한 주관 부 서에 따라 특성화되어 다루어지는 주제들도 있었다. 어린이 식품안전 · 영양 교육을 위해 식품의약품안전처에서 제시된 교재의 경우는 어린이가 선호하는 간식에 다량 함유되어 있 어 과량 섭취시 영양문제가 발생할 가능성이 있는 당, 나트 
30 - 초등돌봄건강식생활 교육

Table 3. Content elements regarding healthy dietary proposed in the Grade 2 Curriculum

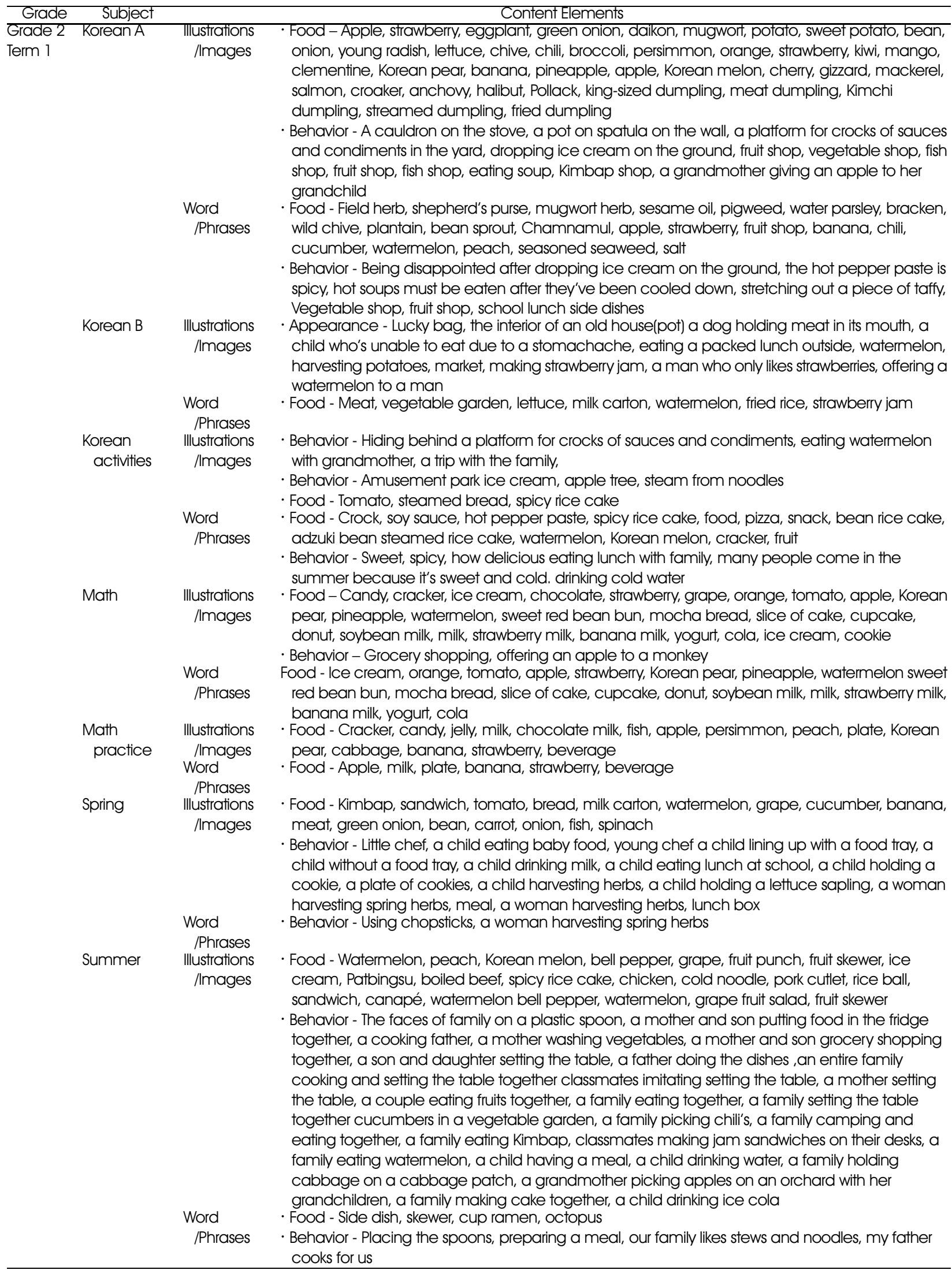


Table 3. continued

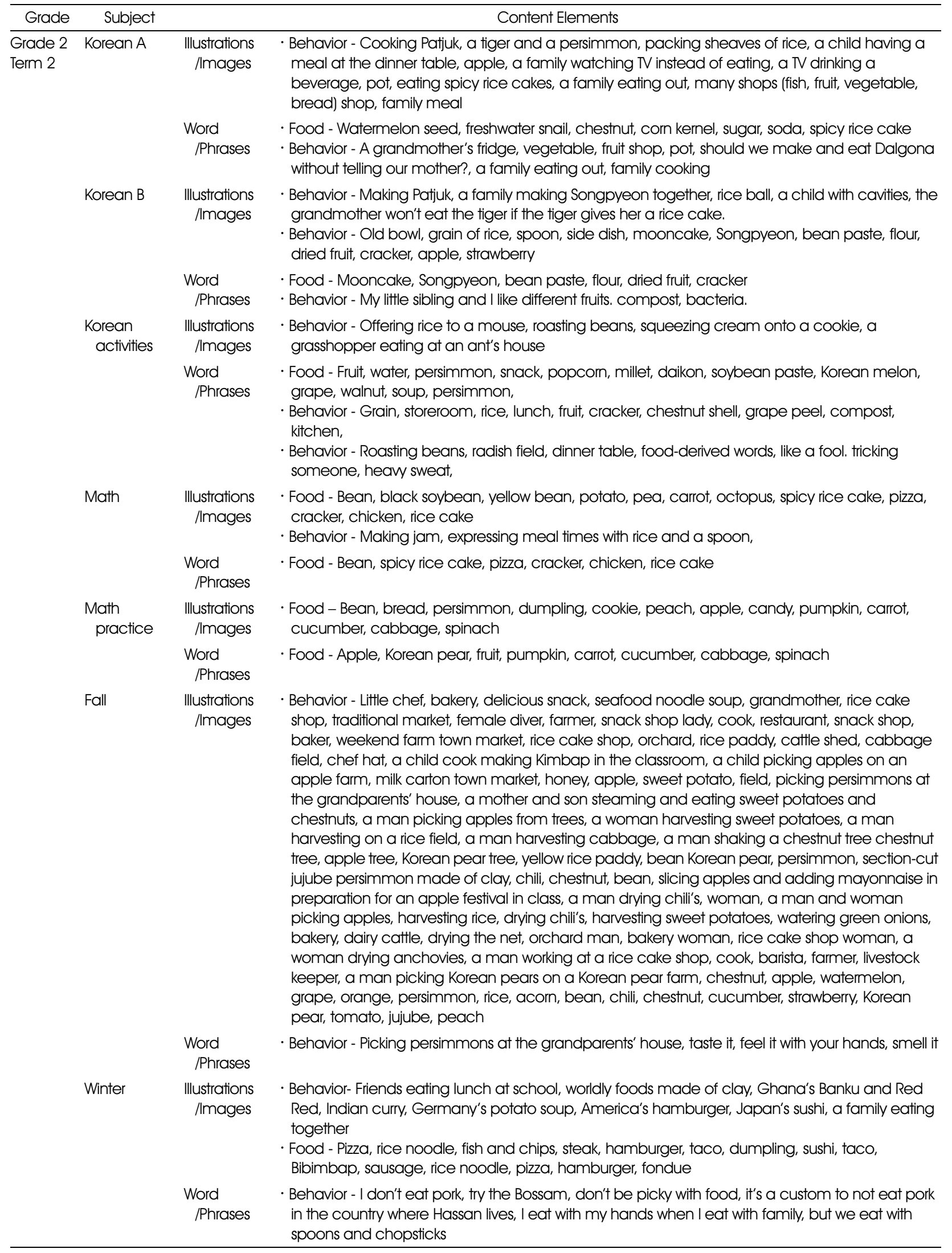


32 - 초등돌봄건강식생활 교육

Table 3. continued

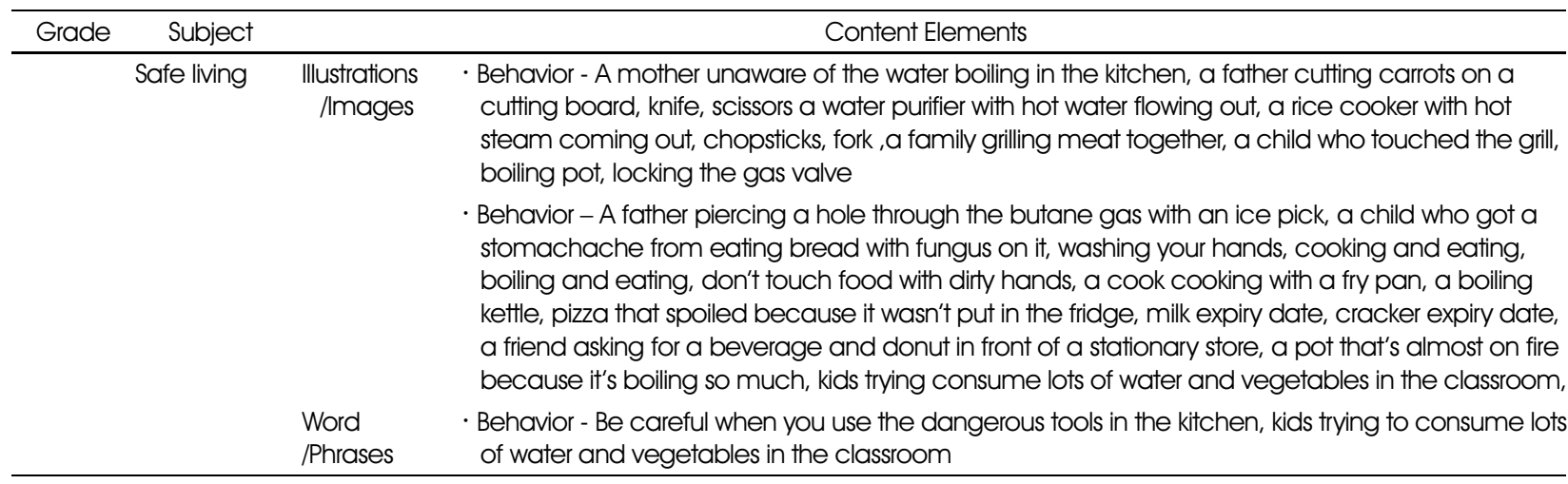

Table 4. Education program for healthy dietary for use in elementary school

\begin{tabular}{|c|c|c|c|}
\hline Teaching material & Manual & PPT & Leaflet \\
\hline $\begin{array}{l}\text { The green diet of the five } \\
\text { senses }\end{array}$ & $\begin{array}{l}\text { Physical activity guide for proper } \\
\text { weight management }\end{array}$ & $\begin{array}{l}\text { Nutrition plus, picky eating story } \\
\text { card }\end{array}$ & Nutrition Plus, Hygiene care \\
\hline Green diet guidelines & $\begin{array}{l}\text { Establishing the healthy weight } \\
\text { that my body wants }\end{array}$ & $\begin{array}{l}\text { Healthy fruit basket } \\
\text {-Eating snacks in a healthy way }\end{array}$ & Healthy weight after school \\
\hline Camp material for the study & $\begin{array}{l}\text { Healthy classroom management } \\
\text { manual }\end{array}$ & $\begin{array}{l}\text { Healthy fruit basket } \\
\text {-What should I eat for a snack? }\end{array}$ & What's a healthy weight? \\
\hline Healthy fruit basket & Green diet guidelines & $\begin{array}{l}\text { Healthy fruit basket } \\
\text {-Fruit story }\end{array}$ & $\begin{array}{l}\text { Nutrition Plus, } \\
\text {-Children Anemia }\end{array}$ \\
\hline Picky eating education & $\begin{array}{l}\text { School nutrition education } \\
\text { manual }\end{array}$ & $\begin{array}{l}\text { Healthy fruit basket } \\
\text {-Establishing a healthy } \\
\text { body }\end{array}$ & $\begin{array}{l}\text { Misunderstandings and prejudices } \\
\text { about healthy weight }\end{array}$ \\
\hline $\begin{array}{l}\text { Happy meal, enjoyable } \\
\text { cooking }\end{array}$ & $\begin{array}{l}\text { School nutritious diet education } \\
\text { manual }\end{array}$ & $\begin{array}{l}\text { Healthy fruit basket } \\
\text {-Children dietary guidelines }\end{array}$ & $\begin{array}{l}\text { Lifelong health of youth, } \\
\text { establishing a healthy weight }\end{array}$ \\
\hline Let's look at food allergies & Let's eat smart and get healthy & $\begin{array}{l}\text { Healthy fruit basket } \\
\text {-My homemade vegetable } \\
\text { cooking }\end{array}$ & $\begin{array}{l}\text { Nutrition plus } \\
\text {-Nutrition management of } \\
\text { underweight Children }\end{array}$ \\
\hline $\begin{array}{l}\text { The food we enjoy with our } \\
\text { five senses }\end{array}$ & & $\begin{array}{l}\text { Nutrition consultation } \\
\text { [Correction of picky eating] } \\
\text { Operation report }\end{array}$ & Be careful of caffeine beverages! \\
\hline $\begin{array}{l}\text { Elementary nutrition } \\
\text { education study group } \\
\text { operation report }\end{array}$ & & That's enough for today! & $\begin{array}{l}\text { Nutrition Plus, } \\
\text {-Nutrition management of my } \\
\text { picky child }\end{array}$ \\
\hline Correct eating, Bright 100's & & $\begin{array}{l}\text { Making a healthy school with bland } \\
\text { flavor }\end{array}$ & Picky eating, food traffic light \\
\hline An exciting diet & & $\begin{array}{l}\text { Nutrition information for multicultural } \\
\text { families }\end{array}$ & Dietary guidelines for Koreans \\
\hline $\begin{array}{l}\text { Kimbap's adventure from } \\
\text { the farm to the dinner table }\end{array}$ & & $\begin{array}{l}\text { Nutrition plus, obesity prevention } \\
\text { activity }\end{array}$ & Healthy fruit story \\
\hline
\end{tabular}

륨, 트랜스지방에 대한 저감화를 위한 교육 내용을 담고 있 었으며, 당, 나트륨, 트랜스지방의 정의와 함유된 식품, 건강 문제, 과잉섭취 예방 방법 등의 내용으로 구성되어 있다. 그 외에, 만화책의 형태로 식생활과 관련된 건강관련 주제와 식 품위생과 관련 안전 주제들로 제시되어 있음을 알 수 있었 다. 또한, 어린이들의 올바른 식생활 의식 함양을 위해 '건강 한 식생활 실천'을 강조한 학교와 집, 마트 등 상황과 장소에 따라 실천할 수 있는 실천항목들도 제시하고 있다.

\section{3. 초등학교 교육 현장 활용 건강식생활 관련 내용 요소}

초등학교 교육과정 및 교과서 그리고 초등학교 현장에서 활용되는 건강식생활 교육프로그램을 분석 자료를 바탕으로 교육 주제 및 내용을 추출한 결과는 Table 5 와 같다. 대주 제는 위생 안전과 관련하여 계절별 관리, 환경관리로 구분하 였고, 식재료는 과일과 채소, 곡류가 추출되었다. 건강과 관 련해서는 골고루 먹기, 열량, 소금, 당, 소화, 운동 등이 다루 어졌다. 
Table 5. Contents of education topics most used in elementary school

\begin{tabular}{|c|c|c|}
\hline Topic & Sub-topic & Educational content \\
\hline \multirow[t]{6}{*}{$\begin{array}{l}\text { Hygiene and } \\
\text { safety }\end{array}$} & Washing your hands & $\begin{array}{l}\text { - When to wash your hands and how to wash your hands properly (8steps) } \\
\text { - The diseases you can contract if you don't wash your hands }\end{array}$ \\
\hline & Brushing your teeth & $\begin{array}{l}\cdot \text { How to brush your teeth properly } \\
\text { - Information regarding foods that are good and bad for your teeth }\end{array}$ \\
\hline & Personal hygiene & $\begin{array}{l}\cdot \text { Why we should keep our bodies clean } \\
\cdot \text { How to keep our bodies clean }\end{array}$ \\
\hline & & - Information regarding keeping the washroom clean \\
\hline & & - Explanation of how to cough properly \\
\hline & & - Don't consume foreign substances \\
\hline \multirow[t]{2}{*}{$\begin{array}{l}\text { Seasonal } \\
\text { health safety } \\
\text { control }\end{array}$} & Summer health safety & $\begin{array}{l}\text { - Behaviors for having a safe summer } \\
\text { - Check the expiry dates, etc. } \\
\text { - During the unpredictable summer weather, eat refreshing foods. }\end{array}$ \\
\hline & Winter health safety & $\begin{array}{l}\text { - Protect your health during the winter } \\
\text { - Practice the methods of protecting your health }\end{array}$ \\
\hline \multirow[t]{5}{*}{$\begin{array}{l}\text { Eating well } \\
\text { (Healthy diet) }\end{array}$} & Eat well & $\begin{array}{l}\text { - What kind of foods should you eat to be healthy? } \\
\text { - An explanation using the food composition bicycle }\end{array}$ \\
\hline & Drink millk & - If you drink milk every day, you'll become healthy \\
\hline & Picky eating prevention & $\begin{array}{l}\text { - Learn about the names and colors of various vegetables } \\
\text { - Become friendly with vegetables } \\
\text { - Touch beans in person } \\
\text { - A lesson on the importance of chewing thoroughly }\end{array}$ \\
\hline & $\begin{array}{l}\text { Don't forget to eat } \\
\text { breakfast }\end{array}$ & $\begin{array}{l}\text { - An explanation about why you must eat breakfast } \\
\text { - What did you have for breakfast? } \\
\text { - What should we do to enjoy our breakfast? }\end{array}$ \\
\hline & Snacks and health & $\begin{array}{l}\text {-Why are snacks important? } \\
\text { - What are my favorite snacks? } \\
\text { - Healthy snacks according to the nutrition traffic light }\end{array}$ \\
\hline \multirow{5}{*}{$\begin{array}{l}\text { Environment } \\
\text { and kitchen } \\
\text { management }\end{array}$} & $\begin{array}{l}\text { Please take care of my } \\
\text { refrigerator }\end{array}$ & $\begin{array}{l}\text { - The importance of refrigerator and freezers, } \\
\text { - Information regarding which foods to put in the freezer }\end{array}$ \\
\hline & Kitchen risks & - Information regarding dangerous items of the kitchen, such as the gas, knife, detergents, etc. \\
\hline & $\begin{array}{l}\text { Understanding food } \\
\text { additives }\end{array}$ & - Types of food additives and how to consume healthy foods \\
\hline & Clear your plate & $\begin{array}{l}\text { - Why is it bad to not finish your food? } \\
\text { - You can separate the compost } \\
\text { - What should you do to finish your food? }\end{array}$ \\
\hline & Eat safe foods & - Information regarding safe foods and foods to avoid \\
\hline Digestion & $\begin{array}{l}\text { A Trip through the } \\
\text { mysterious body, } \\
\text { Importance of } \\
\text { proper eating, } \\
\text { Strong child } \\
\text { (Golden poop) }\end{array}$ & $\begin{array}{l}\text { - The names and roles of the digestive system, the process of digestion } \\
\text { - How is my food digested? }\end{array}$ \\
\hline \multirow[t]{3}{*}{$\begin{array}{l}\text { Fruits and } \\
\text { vegetables }\end{array}$} & $\begin{array}{l}\text { Eat vegetables of } \\
\text { the five senses, } \\
\text { Learn about } \\
\text { vegetables/fruits, } \\
\text { Fruits and vegetables } \\
\text { are delicious }\end{array}$ & $\begin{array}{l}\text { - Become friendly with fruits and vegetables } \\
\text { - What benefits do fruits and vegetables give our bodies } \\
\text { - Information regarding the benefits of vegetables } \\
\text { - Types of fruits and vegetables that come from vegetable gardens } \\
\text { - Look at the color, smell it, touch it, and then talk about how you feel } \\
\text { - Why are the colors of fruits and vegetables different? } \\
\text { - How much vegetables should we eat a day? }\end{array}$ \\
\hline & Colorful foods & $\begin{array}{l}\text { - Information regarding the names and colors of colorful vegetables } \\
\text { - An explanation of our agricultural products }\end{array}$ \\
\hline & $\begin{array}{l}\text { Satisfaction of the five } \\
\text { senses, taste } \\
\text { education }\end{array}$ & A five-sense experience using food ingredients, \\
\hline
\end{tabular}


34 - 초등돌봄 건강식생활 교육

Table 5. continued

\begin{tabular}{|c|c|c|}
\hline Topic & Sub-topic & Educational content \\
\hline Sugar & Reducing sugar & $\begin{array}{l}\text { - Information regarding the sugars that the body absorbs slowly and the sugars that the body } \\
\text { absorbs slowly } \\
\text { - Definition and function of sugars, problems of over consuming sugars } \\
\text { - An explanation of differentiating healthy snacks from high-sugar snacks } \\
\text { - Where does the sweetness come from? Sugar, oligosaccharide, high fructose corn syrup } \\
\text { - Milk and processed milk, the difference in flavor of fruits and fruit juice } \\
\text { - Learn about the sugar content of crackers and beverages. } \\
\text { - Make an effort to reduce sweet taste. }\end{array}$ \\
\hline \multirow{3}{*}{$\begin{array}{l}\text { Grain } \\
\text { /Cereal }\end{array}$} & Grains are good & - Education to promote the interest and learning of various grains \\
\hline & $\begin{array}{l}\text { Many foods are made } \\
\text { with rice }\end{array}$ & $\begin{array}{l}\text { - How does rice end up on our dinner tables? } \\
\text { - Be thankful to the farmers and cooks for the delicious meals } \\
\text { - Learn about the types of rice } \\
\text { - I know how to cook rice } \\
\text { - I can make many delicious foods with rice }\end{array}$ \\
\hline & Growing soybeans & $\begin{array}{l}\text { - The benefits of beans and the structure of bean seeds, } \\
\text { - Information regarding the fruit-yielding process of beans }\end{array}$ \\
\hline Salt & $\begin{array}{l}\text { Learn about salt, } \\
\text { I don't want to at salty } \\
\text { foods }\end{array}$ & $\begin{array}{l}\text { - An explanation of what salt is and what they do } \\
\text {-Where did saltiness come from? } \\
\text { - What do salty foods contain? } \\
\text { - What will salty foods do to my body? } \\
\text { - What should I do to eat bland foods? }\end{array}$ \\
\hline \multirow[t]{2}{*}{ Calories } & $\begin{array}{l}\text { Body composition and } \\
\text { weight management }\end{array}$ & $\begin{array}{l}\text { - Body composition, } \\
\text { - Healthy weight of children, the correct way to manage body weight }\end{array}$ \\
\hline & Food with less calories & $\begin{array}{l}\text {-What are calories? } \\
\text {-What do high-calorie foods contain? }\end{array}$ \\
\hline Exercise & $\begin{array}{l}\text { Healthy children with } \\
\text { tall height and strong } \\
\text { bodies }\end{array}$ & $\begin{array}{l}\text { - Do you like to exercise? What kind of exercise do you engage in? } \\
\text { - What kind of changes does exercise make on our bodies? } \\
\text { - Where do we get our strength when we exercise? }\end{array}$ \\
\hline \multirow[t]{4}{*}{ Food culture } & $\begin{array}{l}\text { Have good table } \\
\text { manners } \\
\text { Housework and family }\end{array}$ & $\begin{array}{l}\text { - Information regarding the proper use of chopsticks } \\
\text { - What do your friends look like when they eat? } \\
\text { - How is the food etiquette in foreign countries? } \\
\text { - Table manners at restaurants } \\
\text { - My eating habits } \\
\text { - The preparation and clearing of meals } \\
\text { - Learn about various cultures }\end{array}$ \\
\hline & Our traditional foods & $\begin{array}{l}\text {-What are traditional foods? } \\
\text { - What do our country's traditional foods contain? Kimchi, hot pepper paste. Soybean paste, } \\
\text { Japchae, etc. } \\
\text { - Which one's my favorite? }\end{array}$ \\
\hline & Chuseok & $\begin{array}{l}\text { - Prepare for Chuseok } \\
\text { - Making Songpyeon, making pancakes } \\
\text { - Clean the plates for the memorial service } \\
\text { - Carry out the memorial service }\end{array}$ \\
\hline & Traditional culture & $\begin{array}{l}\text { - Our traditional foods } \\
\text { - Preparing birthday foods } \\
\text { - Our country's foods that foreigners like }\end{array}$ \\
\hline \multirow[t]{3}{*}{$\begin{array}{l}\text { Agricultural } \\
\text { products }\end{array}$} & $\begin{array}{l}\text { Eat our healthy } \\
\text { agricultural products }\end{array}$ & $\begin{array}{l}\text { - Let's learn about our agricultural products } \\
\text { - How do imported products arrive in our country from so far away? }\end{array}$ \\
\hline & Home gardening & $\begin{array}{l}\text { - Which food products come from nature? } \\
\text { - Information and education regarding where vegetables grow } \\
\text { - Life is precious, watering plants } \\
\text { - Plant seeds - Monitoring and recording the seed planting } \\
\text { - Raise plants - Plant care }\end{array}$ \\
\hline & & $\begin{array}{l}\text { - Be thankful to those who harvested them } \\
\text { - Fall ruits - Guessing the names of fruits }\end{array}$ \\
\hline
\end{tabular}


Table 5. continued

\begin{tabular}{|c|c|c|}
\hline Topic & Sub-topic & Educational content \\
\hline \multirow[t]{2}{*}{$\begin{array}{l}\text { Our country and } \\
\text { neighboring } \\
\text { countries }\end{array}$} & $\begin{array}{l}\text { The foods of our } \\
\text { country and other } \\
\text { countries }\end{array}$ & $\begin{array}{l}\text { - An open world where I reach out my hand first } \\
\text { - Differences between various countries (food ingredients, flavor, etc.) }\end{array}$ \\
\hline & Family & $\begin{array}{l}\text { - A multicultural festival } \\
\text { - Make foods from various countries }\end{array}$ \\
\hline \multirow{2}{*}{$\begin{array}{l}\text { Grocery } \\
\text { shopping }\end{array}$} & Grocery shopping for & - Grocery shopping for foods that make our bodies sturdy \\
\hline & $\begin{array}{l}\text { sturdy bodies, safe } \\
\text { purchasing }\end{array}$ & $\begin{array}{l}\text { - Grocery shopping for safe foods } \\
\text { - Understanding nutrition information }\end{array}$ \\
\hline
\end{tabular}

문화면에서는 우리나라의 식사예절과 추석 등을 통해 전 통음식을 다루고 있고 이웃나라 축제 및 음식문화를 소개하 고 있는 것으로 분석되었다.

\section{4. 초등 돌봄 교실 현장 전문가 심층 면담}

초등 저학년 돌봄 교실 현장 전문가는 돌봄 교실 담당 교 사 5 인, 영양교사 1 인, 돌봄 전담사 4 인들로 구성되었으며, 사전 질문지를 통해 1 차면담을 진행하였으며, 이어 2 회차 심 층 면담을 통하여 최종 결과를 도출하였다 (Table 6). 초등 돌봄 교실에서 건강식생활 교육은 무엇보다 가장 우선적으 로 필요한 프로그램으로 면담결과 도출되었다. 내용에 대한 요구로는 안전하고 영양적인 간식제공과 보육의 의미인 교 육과정으로서 가정과의 연계 등이 제시되었다. 또한 저학년 에 맞는 학습수준과 체험 및 놀이 등의 교육방법에 대한 내 용을 요구하였다. 건강식생활 교육 프로그램의 목표는 초등 저학년 돌봄 교실 학생들의 특성을 반영하여 맞벌이 · 저소 득층 - 한부모 가정의 학부모들이 안심하고 양육할 수 있는 안전한 환경 조성 및 초등 교육과정 및 교과서 목표를 기반 해야 하는 것으로 나타났다. 즉 2015 개정 교육과정의 주요 내용에서 제시된, ‘창의융합형 인재'의 덕목인 ‘인성교육' 그 리고 ‘건강'과 ‘식생활'을 담아낼 수 있어야 하는 것으로 나 타났다. 즉 돌봄 수요를 충족하고 학생과 학부모가 만족하는
질 높고 안전하고 건강한 식생활교육이 될 수 있도록 그 목 표를 설정해야 함을 알 수 있었다. 교육주제는 앞서 분석된 건강식생활과 초등 교육내용과 유사하게 도출되었는데 특히 건강과 관련된 내용이 주를 이루어 골고루 먹기, 아침밥먹 기, 채소와 과일, 건강한 간식 등의 주제가 도출되었다.

\section{5. 초등 저학년 돌봄 교실 건강식생활 교육 프로그램 목표 설정}

초등 저학년 돌봄 교실 건강식생활 교육을 위한 목표설정 은 2015 초등 교육과정 및 교과서, 초등학교 현장 활용 교 육 활동 주제 그리고 돌봄 교실 현장 전문가들의 심층 면담 을 통하여 설정하였다. 목표는 안전한 식생활이 될 수 있는 위생관리와 미래의 건강한 성인으로 성장할 수 있는 영양관 리를 위하여 생활 속에서 문제가 되는 식습관 행동을 확립하 고자 하였다. 또한 초등학생 저학년의 발달 단계에 따른 내 용과 수준의 범위를 고려하여 목표를 설정하였다. 초등 저학 년 돌봄 교실 건강식생활 교육목표는 다음과 같다.

첫째, 돌봄교실의 안전한 보살핌의 기능을 수행한다. 둘째, 창의성 함양을 통하여 특기와 적성을 탐색한다. 셋째, 협동심 함양으로 인성교육을 실천한다.

넷째, 즐거움과 흥미로운 활동으로 건강유지 및 식생활 가 치를 체득한다.

Table 6. Focus group interview with expert of after-school care, lower grade in elementary school

\begin{tabular}{|c|c|c|}
\hline Requirement content & Educational objectives & Educational topics \\
\hline $\begin{array}{l}\text { - The need for safety education is a top priority } \\
\text { - Providing them with basics foods and related lifestyle } \\
\text { education is needed } \\
\text { - Specialized guidance that match the children's } \\
\text { developmental stages and learning levels is needed } \\
\text { - Effective methods through activities and play are } \\
\text { needed } \\
\text { - Information regarding safe and nutritional snacks is } \\
\text { needed } \\
\text { - It should be connected to family life education while } \\
\text { being more professional than what is taught at home } \\
\text { - We need to ensure that the students' interests and } \\
\text { responses are connected to family life education }\end{array}$ & $\begin{array}{l}\text { The objective is to provide safe and } \\
\text { enjoyable after-school classes as an } \\
\text { extension of school education so that the } \\
\text { lower-grade elementary students can grow } \\
\text { into healthy, creative, and talented } \\
\text { individuals. } \\
\text { 1. Provide safe care } \\
\text { 2. Explore skills and aptitudes by fostering } \\
\text { creativity } \\
\text { 3. Provide character education by fostering } \\
\text { cooperation } \\
\text { 4. Learn the value of health care and eating } \\
\text { habits through fun and exciting activities }\end{array}$ & $\begin{array}{l}\text { 1. Eat various foods } \\
\text { 2. Eat breakfast } \\
\text { 3. Fruits and vegetables } \\
\text { 4. Delicious snacks that are } \\
\text { good for your health } \\
\text { 5. Healthy body weight } \\
\text { 6. Clean body } \\
\text { 7. Food and digestion orage } \\
\text { 8. Safe food selection and } \\
\text { storage } \\
\text { 9. Our country's foods } \\
\text { 10. Table manners }\end{array}$ \\
\hline
\end{tabular}


36 - 초등돌봄건강식생활 교육

Table 7. Content System of healthy dietry education in after-school care, lower grade in elementary school

\begin{tabular}{|c|c|c|c|}
\hline Section & Subject & Achievement goal & Content element \\
\hline \multirow[t]{2}{*}{ I. Nutritious diet } & Dietary balance & $\begin{array}{l}\text { - Dietary balance can be achieved through } \\
\text { regular consumption of various foods. } \\
\text { - Understand various foods as well as their } \\
\text { characteristics and nutritious functions. } \\
\text { - Understand care classroom snacks and } \\
\text { make them benefit our bodies by } \\
\text { practicing healthy snacking behavior. }\end{array}$ & $\begin{array}{l}\text { 1-1. Eat various foods. } \\
\text { I-2. Eat breakfast. } \\
\text { I-3. Eat vegetables and fruits. } \\
\text { 1-4. Delicious snacks that are good for } \\
\text { your body }\end{array}$ \\
\hline & Healthy body weight & $\begin{array}{l}\text { - I will self-diagnose my current body weight } \\
\text { and manage it to a healthy range. }\end{array}$ & I-5. Healthy body weight \\
\hline \multirow[t]{2}{*}{$\begin{array}{l}\text { II. Food hygiene } \\
\text { and health }\end{array}$} & Digestive \& absorption & $\begin{array}{l}\text { - Understand the processes following our } \\
\text { consumption of food and practice healthy } \\
\text { behavior in order to have a sturdy body. }\end{array}$ & $\begin{array}{l}\text { II-1. Clean body, Healthy body } \\
\text { II-2. Food that has entered our body }\end{array}$ \\
\hline & Food hygiene & $\begin{array}{l}\text { - Understand and practice safe food } \\
\text { selection and storage. }\end{array}$ & $\begin{array}{l}\text { II-3. What is healthy food } \\
\text { II-4. Food selection and storage }\end{array}$ \\
\hline \multirow[t]{2}{*}{ III. Food culture } & $\begin{array}{l}\text { Our agricultural products and } \\
\text { traditional foods }\end{array}$ & $\begin{array}{l}\text { - Understand the value of our agricultural } \\
\text { products as well as the production and } \\
\text { consumption processes. } \\
\text { - Understand the excellence of our } \\
\text { agricultural products and food culture and } \\
\text { strive to make it develop further. }\end{array}$ & $\begin{array}{l}\text { III-1. Our land, Our grain } \\
\text { III-2. Enjoy traditional foods }\end{array}$ \\
\hline & Table manners & $\begin{array}{l}\text { - Understand the value of our country's } \\
\text { dietary culture and make an effort to } \\
\text { maintain the traditions in our daily lives. }\end{array}$ & III-3. Have table manners \\
\hline
\end{tabular}

\section{6. 초등 저학년 돌봄 교실의 건강식생활 교육 내용 체계}

초등 돌봄 건강식생활 교육 목표달성을 위한 교육 내용을 Table 7에 제시하였다. [영양식생활] 과 [식품 위생과 건강] 그리고 [음식 문화]라는 3가지 영역으로 구분하고 주제는 각 영역별로 식생활 균형, 건강제중, 소화흡수, 식품위생, 우리 농산물과 전통음식, 식사예절 등으로 구성하였다. 각 주제에 대해 성취목표를 제시하였고 이를 달성할 수 있는 12 개의 내 용요소를 작성하였다. [영양식생활] 영역은 ‘식생활균형’과 '건강체중'을 주제로 하여 ‘골고루 먹어요', '아침밥을 먹어 요’, ‘채소와 과일을 먹어요', 그리고 ‘몸에 좋고 맛있는 간 식'으로 내용을 구성하였다. [식품 위생과 건강] 영역은 ‘소 화흡수'와 ‘식품위생'으로 주제를 나누어'깨끗한 몸. 튼튼한 몸, ‘우리 몸에 들어온 음식', ‘무엇이 안전한 음식일까?’, ‘식 품선택과 보관'으로 내용을 구성하였다. [음식문화 영역]은 ‘우리 농산물과 전통음식'과 '식사예절'을 주제로 하여 ‘우리 땅, 우리 곡식', '전통음식을 즐겨요', ‘식사예절을 지켜요'로 내용을 구성하였다.

\section{요약 및 결론}

본 연구에서는 초등 저학년 돌봄 교실에서 적용 가능한 건 강식생활 교육프로그램의 목표를 설정하고 이를 이루기 위 한 교육 내용을 구성하였다.
1. 초등 교육과정 내 건강식생활 학습 요소는 몸과 마음의 건강을 유지하는 내용으로 제시되어 있으며, 또한 계절에 대 한 내용으로 날씨 변화에 따른 건강관리에 대한 내용을 다루 고 있다.

2. 교과서 분석에서는 국어, 국어활동, 수학, 수학익힘, 봄, 여름, 가을 그리고 겨울 등의 교과서에 이미지와 삽화 그리 고 낱말과 문구 등으로 채소와 과일, 곡류, 간식 등의 식품이 주로 제시되고 있고 식재료의 수확과 조리, 가정에서의 식생 활 행동과 또래 집단에서 나타나는 행동 등이 주로 제시되고 있다.

3. 현재 초등학교 현장에서 활용되고 있는 건강식생활 관 련 교육 프로그램은 관련 행정 부서에서 교재, 매뉴얼, $\mathrm{PPT}$ 및 리플렛 등 다양한 교육 도구로 개발, 보급되어 있다.

4. 교육과정, 교과서, 행정부서보급 내용을 모두 분석한 결 과 위생안전, 건강, 문화의 영역으로 분류되었으며 각 영역 별 주제를 다양하게 다루고 있다.

5. 초등 돌봄 교실 관련 전문가 면담에서는 초등 돌봄 교실 에서 건강식생활 교육이 무엇보다 가장 우선적으로 필요한 프로그램으로 도출되었다. 내용에 대한 요구로는 안전하고 영양적인 간식제공과 보육의 의미인 교육과정으로서 가정과 의 연계 등이 제시되었다.

6. 초등 돌봄 건강식생활 교육의 목표는 '안전한 보살핌의 기능을 수행', ‘창의성 함양을 통하여 특기와 적성을 탐색', ‘ 
협동심 함양으로 인성교육을 실천’, ‘즐거움과 흥미로운 활 동으로 건강유지 및 식생활 가치를 체득'으로 설정하였다.

7. 목표를 성취할 수 있는 교육 내용체계를 [영양식생활] 과 [식품 위생과 건강] 그리고 [음식 문화]라는 3가지 영역 으로 구분하고 주제는 각 영역별로 식생활 균형, 건강제중, 소화흡수, 식품위생, 우리 농산물과 전통음식, 식사예절 등으 로 구성하고 12 개의 내용요소로 교육과정을 구성하였다.

본 연구는 초등 저학년 돌봄교실에서 가장 최우선으로 필 요한 교육으로 강조되고 있는 건강식생활교육의 목표 설정 과 교육내용을 구성하여 이를 돌봄 교실에서 원활하게 적용 하기 위한 근간을 마련하고자 하였다. 설정된 목표와 구성된 교육내용이 효과적으로 적용되어, 돌봄 교실에 참여한 초등 학교 저학년 학생들이 건강한 성장발달과 함께 창의융합형 인재로 성장할 수 있도록 하기 위해서는 무엇보다 돌봄 가이 드의 역할이 중요하며 향후 이들을 위한 가이드라인의 필요 성이 절대적이다. 이 가이드라인은 주제에 따른 학습 개요를 넣어 돌봄 전담사가 단원에 맞는 주제, 교육의도, 학습목표, 학습자료, 활동내용, 지도상의 유의점을 잘 파악할 수 있도 록 해야 할 것이다. 또한 교육 컨텐츠 개발에 있어서는 돌봄 교실에 참여하는 초등학교 저학년 학생들의 흥미를 유발시 킬 수 있는 동기유발 자료의 구성이 필요하며, 교육 내용에 는 다양한 활동들을 제시하여 학생들이 자기 주도적으로 학 습할 수 있도록 하며, 그러한 과정에서 문제해결력, 의사결 정능력, 사고력, 탐구력 등이 길러지도록 구성하여야 할 것 이다. 또한 학생들이 쉽게 이해할 수 있도록 다양한 사진이 나 삽화를 활용하는 것이 필요하며, 학습된 내용을 이해하고 있는지 정리, 평가할 수 있도록 체계화되어야 할 것이다.

\section{감사의 글}

This research was supported by a grant from Korea Health Promotion Institution in 2016.

\section{References}

1. Kim SD, Yang AK. A study on the recent movement \& implications of the elementary school after- school child care service policy in Korea \& Japan. Korean J Jpn Educ 2014; $18(2): 41-60$.
2. Kim YK, Park JY, Song HR. A study on the development and management of a childcare service program for the dual-income family: a focus on the service of nongovernmental institutions. Fam Environ Res 2010; 48(5): 145-155.

3. Seoul Dongjak Gwanak District Office of Education. Guidance on the operation of elementary care classroom [Internet]. Seoul Dongjak Gwanak District Office of Education; 2015 [cited 2015 May 20]. Available from: http://dgedu.sen.go.kr/CMS/notice/ notice01/notice0104/1266182_5090.html.

4. Lee SJ, Hong JH. Childhood Obesity Prevention Programs and Challenges in After-school Care of Elementary Schools-. Korea Health Promotion Institution; 2016. 11. Report No. 2508-4844.

5. Her ES. Interrelations among snack preference, purchasing behaviors and intake in upper grade elementary school students: compared by the gender and TV watching time. Korean J Community Nutr 2013; 18(5): 429-441.

6. Mo YS. Evaluation of nutrition education effectiveness to reduce sodium intake for elementary school students based on health belief model [master's thesis]. Yonsei University; 2012.

7. Kim JW, Lee EJ. Evaluation of dietary habits and dietary life competency of elementary school students. J Korean Pract Art Educ 2014; 27(4): 17-37.

8. Paik JJ, Lee HS. Dietary behaviors, food preferences and its relationships with personality traits in sixth grader's of elementary school. Korean J Community Nutr 2004; 9(2): 135141.

9. Kang MH, Yoon KS. Elementary school students' amounts of sugar, sodium, and fats exposure through intake of processed food. J Korean Soc Food Sci Nutr 2009; 38(1): 52-61.

10. Seong EJ. Establishment of roadmap for intervention study of adolescent obesity to prevent and control metabolic disease. Cheongju Disease Management Headquarters; 2016. 3. Report No. 11-1352173-000295-01.

11. OH KJ. Recognition of parents on special act for child protection in food safety and management: focused on elementary school in Gyeonggi province area [master's thesis]. Chung-ang University; 2014.

12. Lee YS. Development of dietary life education program through integral approach [master's thesis]. Daegu National University of Education; 2009.

13. Yun JS, Lyu ES. Satisfaction and perception of nutrition education by elementary school students. Korean Soc Food Sci Nutr 2012; 41(9): 1259-1264.

14. Lee SJ, Hong JH. Childhood Obesity Prevention Programs and Challenges in After-school Care of Elementary Schools-. Korea Health Promotion Institution; 2016 11. Report No. 2508-4844.

15. Lee YM, Park HN. The effectiveness of $\mathrm{Na}$ education program in elementary school: six month follow-up study. Korean J Community Nutr 2010; 15(5): 603-613. 